\title{
Australia's new guidelines
}

\section{Sydney}

THE Australian Vice-Chancellors Committee (AVCC) has released guidelines aimed at helping universities deal with academic fraud "to ensure that the integrity of Australian university research was not damaged by the few cases of academic fraud highlighted recently in Australia, the United States and the United Kingdom." The AVCC guidelines define the types of academic fraud and the procedures for dealing with allegations of fraud; defined to include fabrication of data, plagiarism and the publication of misleading statements regarding authorship. The guidelines recommend that all authors must sign a form confirming their involvement in a paper before publication.

The report, written by Professor David Caro, former Vice-Chancellor of the University of Melbourne, puts the onus squarely on supervisors to ensure the validity of students' work and places restrictions on the number of students one person can supervise. If allegations of fraud or misconduct are made, the AVCC recommends that the staff member concerned be informed in writing and given details of the complaint. The staff member has thirty days to respond to the ViceChancellor.

The new guidelines change the circumstances under which an inquiry terminates Under present university employment

conditions, an investigation must end if the person under investigation resigns. In 1987, for example, investigation of allegations that Professor Michael Briggs, Dean of the Medical School at Deakin University in Melbourne, fabricated data on oral contraception were halted when Briggs took early retirement and moved to Spain. Under the AVCC recommendations, if the accused investigator resigns, the university must convene an inquiry to report on the status of the research in question and on any remedial action needed to protect students, academic colleagues and the public. This includes contacting journals in which allegedly fraudulent papers have been or are about to be published and funding bodies which have contributed to the research

The Caro report stresses "absolute confidentiality and reasonable speed in the early stages of an investigation to protect both the complainant and accused" but leaves decisions on partial disclosures in individual cases to vice-chancellors, who are also responsible for authorizing preliminary investigations and determining the form of the investigation. The guidelines, according to Caro, are a preventive measure rather than a response to escalating levels of fraud in Australian universities. "There have only been three or four examples of fraud in this country".

Tania Ewing INTERNATIONAL COOPERATION

\section{Japan still an island academically}

Washington

DESPITE its scientific achievments, Japan appears still not fully integrated into the world academic community when new data on who Japanese work with, and who they cite in their papers, are considered.

Statistics charting the gradual internationalization of research are reported in the new issue of the US National Science Board's biennial report, Science and Engineering Indicators - 1989. As shown above, all the major western science nations have come close to doubling the percentage of their papers that are coauthored with foreign scientists over the last decade. But Japan has a far lower rate of foreign co-authorship than any other western nation.

Statistics on who Japanese cite in their papers come from an Institute for Scientific Information (ISI) survey published in the latest issue of the journal Science Watch (February 1990).

ISI analysed 2.92 million citations made between 1984 and 1988 to some 897,000 papers published in 1984. After correcting for differences in the total numbers of papers from each country, ISI found that the scientists of every nation tend to refer to work from fellow countrymen more often than to work from people elsewhere. But the preference for self-citation is most pronounced in Japan. Citation links between Japan and North America or the

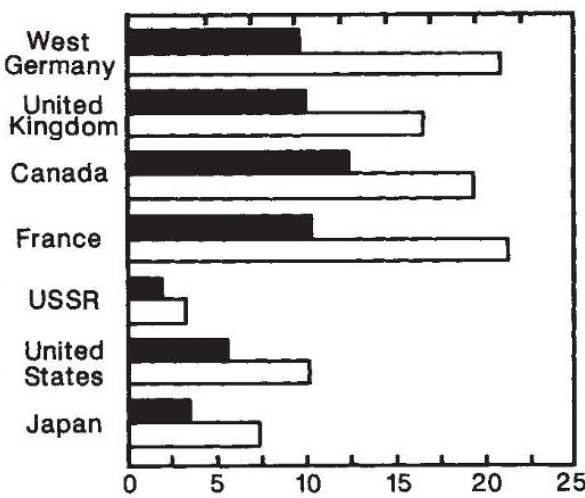

(Per cent internationally coauthored) Internationally co-authored articles by country: 1976 and 1986

European Community are only half as strong as the links between North America and the European Community.

Alun Anderson

\section{New setback for Ariane}

\section{Parls}

EUROPE's commercial satellite launch consortium, Arianespace, suffered a setback last Friday when one of its new generation Ariane-4 launchers exploded shortly after lift-off. The payload of two Japanese telecommunications satellites was destroyed. This was the fifth failure in the thirty-six missions since the first Ariane launch in September 1979.

According to a communique issued from the Arianespace headquarters outside Paris, a sudden drop in pressure occurred in the combustion chamber of 1 of the 4 strap-on boosters of the first-stage propulsion system, just over 6 seconds after lift-off. Automatic compensation by the other three boosters, to correct for the loss of thrust, caused "excessive loads" on the launcher, leading to the explosion at about $9 \mathrm{~km}$ altitude, $12.5 \mathrm{~km}$ from the launch pad in Kourou, French Guyana.

A committee of enquiry is being set up, with representatives from the different aerospace manufacturers involved in Arianespace together with representatives of the European Space Agency. The composition of this committee should be decided by Tuesday 27 February. In the meantime, "detailed technical analysis of the failure" has been started, and future launches are to be suspended until "a complete understanding of the accident has been reached and corrective actions defined and implemented".

One of the satellites on board, BS- $2 x$, was meant to back up and eventually replace the BS-2b satellite which is used for direct broadcasting to the entire Japanese archipelago. The satellite was also to be used for experimental trials of Japanese high-definition television broadcasting technology, pending the launch later this year of BS-3 by a Japanese H1 rocket. The other satellite was Superbird B, a telecommunications satellite built for the Japanese Space Communications Corporation.

Having won over 50 per cent of world commercial launches while the US competition was out of the race following the shuttle disaster, Arianespace is now facing a tougher time in the $1990 \mathrm{~s}$. Not only is the US competition back, with General Dynamics' Atlas Centaur launcher, but the Soviet Union, China and Japan also want a share of the limited market.

Nevertheless, Arianespace still has an order book of 32 satellites, worth about $\$ 2,200$ million, awaiting launch and hopes to make up for the lost time within twelve months - provided of course that the problem is not as knotty as the one affecting the third-stage motor in May 1986 that stopped all Ariane launches for 14 months.

Peter Coles 